Journal of Animal and Veterinary Advances 11 (6): 831-840, 2012

ISSN: $1680-5593$

(C) Medwell Journals, 2012

\title{
Analysis of Cattle Raising and Institutional Perspectives Regarding Collective Action in the El Ocote Biosphere Reserve, Chiapas, Mexico
}

\author{
${ }^{1}$ H. Gomez-Castro, ${ }^{1}$ F. Guevara-Hernandez, ${ }^{2}$ M.H. Hernandez-Lopez, \\ ${ }^{3} \mathrm{~J}$. Nahed-Toral, ${ }^{4} \mathrm{~L}$. Rodriguez-Larramendi and ${ }^{1} \mathrm{R}$. Pinto-Ruiz \\ ${ }^{1}$ Faculty of Agronomic Sciences, Autonomous University of Chiapas, \\ Research Group on Agroforestry, Carretera Ocozocoautla-Villaflores, \\ km. 84.5, Apdo. Postal 78, CP 30470 Villaflores, Chiapas, Mexico \\ ${ }^{2}$ Faculty of Agronomic Sciences, Autonomous University of Chiapas, Mexico \\ ${ }^{3}$ El Colegio de la Frontera Sur, San Cristobal de las Casas, Chiapas, Mexico \\ ${ }^{4}$ Institute for Agricultural Research Jorge Dimitrov, Cuba, Wisconsin, US
}

\begin{abstract}
The objective of this study was to analyze the perceptions of representatives of government agencies and educational institutions regarding problems related to cattle raising in the El Ocote Biosphere Reserve. Through a structural analysis, we identified and prioritized problems which due to their joint relevance, require immediate attention in order to elaborate inter-institutional plans of action which would contribute to the sustainability of cattle raising systems in natural protected areas. Problems in the zone of power (fairly uninfluenced by other problems but which highly influence other problems) were the following: lack of interinstitutional coordination with a motricity index of $10.7 \%$ and a dependence index of $3.31 \%$, lack of public policies which promote environmentally friendly cattle raising with a motricity index of $9.09 \%$ and a dependence index of $7.74 \%$ and lack of organization among producers with a motricity index of $8.26 \%$ and a dependence index of $4.13 \%$. A prioritization of the problems illustrates the importance of the institutions working together to seek solutions to those problems of greater motrocity in order to transcend currently prevalent force fields. Through collective action, the institutions should collectively propose actions and strategies to decision makers, legislators and other political actors in favor of sustainable cattle raising. Furthermore, there is a need for institutions to foment organization among producers and institutions in order to enhance the impact of projects. Meanwhile, institutions should transcend unilateral interests which often hinder efforts of representatives of institutions which work within the El Ocote Biosphere Reserve.
\end{abstract}

Key words: Institutional perception, natural protected areas, sustainable cattle raising, Silvopastoral Systems in Mexico, political actors, Cuba

\section{INTRODUCTION}

In Chiapas as in other regions of Mexico and the rest of the world, some conservation agencies and research institutions agree on the importance of reconciling natural resource use and conservation without diminishing productivity of agricultural systems. Nevertheless, it is often difficult for actors such as government agencies, non-governmental organizations and research institutions (hereafter referred to simply as institutions) to reconcile agendas, strategies and resources in order to reach consensus regarding actions necessary to achieve these objectives (Wells, 1983; Murphy, 1990; Gerritsen, 2002). For this reason, it is important to analyze the points of view of institutional actors with respect to the problems related to cattle raising and obstacles which impede multiinstitutional efforts (Mosse, 1999, 2004) and above all, propose efficient mechanisms for achieving appropriate natural resource management, particularly in small communities which depend on agriculture and cattle raising in particular in Natural Protected Areas (NPA) (Pijnenburg, 2004). Institutional actors often differ in their focuses and priorities of projects in such communities. Therefore, a classification and prioritization of problems would allow for unifying institutional visions in order to create, among producers, a platform of coordinated actions oriented toward a common objective as suggested by Gaventa (2004) and Guevara (2007).

Corresponding Author: H. Gomez-Castro, Faculty of Agronomic Sciences, Autonomous University of Chiapas, Research Group on Agroforestry, Carretera Ocozocoautla-Villaflores, km. 84.5, Apdo. Postal 78, CP 30470 Villaflores, Chiapas, Mexico 
This study addresses the results of a community project in the buffer zone of the El Ocote Biosphere Reserve in which Silvopastoral Systems were established through the Farmer Field Schools methodology (Braun et al., 2000) in order to strengthen local capabilities regarding sustainable cattle raising. Various conservation agencies and research institutions of the state of Chiapas participated in this project, proposing practices to address two generally contradictory aspects: cattle production and natural resource conservation in NPA's. Interinstitutional participation generally arises as a response to accelerated growth of extensive cattle raising on the periphery of nature reserves in an attempt to remedy historic lack of cooperation among institutions which work with protected areas, since cattle raising has been considered to be one of the principal threats to natural resource conservation (CONANP-SEMARNAT, 2001).

After 5 years of fieldwork in the El Ocote Reserve, we set out to study the effects of cattle raising in a community by reviewing relevant social, environmental, economic and agricultural documents interviewing producers as to their perceived benefits and observing the local cattle production system (Gomez et al., 2011, 2010; Nahed-Toral et al., 2010). In this manner, we hoped to gather necessary information for proposing strategies to strengthen this community project (Hernandez, 2009).

The objective of this study is to analyze the perceptions of representatives of conservation agencies and research institutions regarding cattle raising in the El Octote Biosphere Reserve by applying structural analysis (Mojica, 1991) in order to identify and prioritize problems which, due to their joint relevance, require immediate attention in order to be able to elaborate inter-institutional plans of action which contribute to sustainability of cattle raising systems in NPA's. This methodology has been previously used in studies by Gomez (1996) and Nahed (1999) in which the researchers characterized problems related to cattle raising in different regions which in turn has allowed for prioritizing attention to problems based on interdependence among these problems and the capacity to remedy certain problems by addressing others.

In order to analyze the results, we begin with theoretical-conceptual postulates proposed by Nuijten (2003, 2004, 2005) and Guevara-Hernandez et al. (2011) with respect to interactions among problems related to a given development situation and differing visions of institutional representatives regarding development and strategies for resolving these problems. These conflicting visions automatically give rise to force-fields (manifestations of power according to Bourdieu (1985) which modify working relations or spaces of action
(Mattiace, 2001) especially if the institutional representatives lack sufficient experience, capabilities and methods to stimulate creation of collective platforms.

To understand this analysis, it is important to consider the proposal of Long (2001), Long and Villareal (1994) and Long and Long (1992) with respect to the actors participating in design and implementation of development projects which facilitate creation of spaces and relations which transcend the efforts and policies of each participating institution.

Therefore this research, besides systematically and methodologically identifying priority spaces for collective action in order to address problems related to cattle raising in the community also identifies the principle obstacles which arise as a result of conflicting perceptions of the diverse institutions which implement projects in this particular social and administrative area.

\section{MATERIALS AND METHODS}

Location of the study area: The Tzotzil Maya community Ach' lum is located in buffer zone to the Northeast of the $\mathrm{El}$ Ocote Biosphere Reserve (REBISO) which in turn is located in the Western extreme of the Central socioeconomic region of the state of Chiapas, Mexico. The El Ocote Reserve, located between $16^{\circ} 45^{\prime} 42^{\prime \prime}$ and $17^{\circ} 09^{\prime} 00^{\prime \prime}$ North Latitude and $93^{\circ} 54^{\prime} 19^{\prime \prime}$ and $93^{\circ} 21^{\prime} 20^{\prime \prime}$ West longitude includes parts of the municipalities of Ocozocoautla de Espinosa, Cintalapa de Figueroa, Tecpatan de Mezcalapa and Jiquipilas and has a total surface of 101,288-15-12.5 ha (Fig. 1).

Sources of information and systematization: Secondary information from the community Ach' lum was analyzed including documents such as project proposals, diagnostic studies, minutes of workshops and meetings,

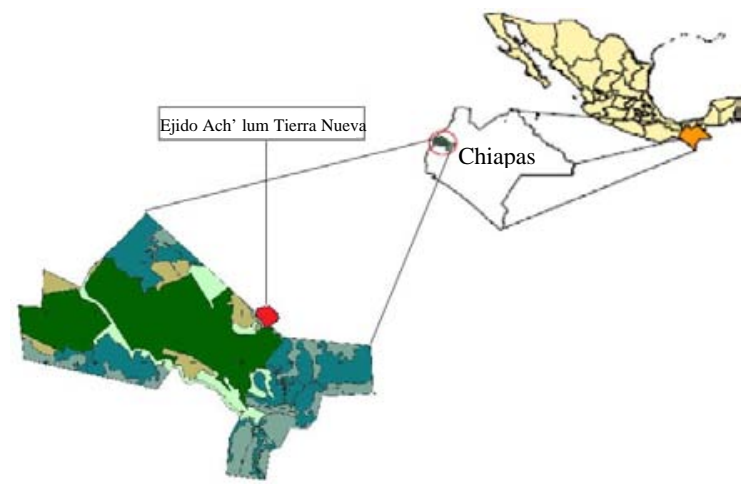

Fig. 1: Geographic location of the community Ach' lum within the El Ocote Biosphere Reserve. Administration of the $\mathrm{El}$ Ocote Biosphere Reserve, Ocozocoautla, Chiapas 
etc. Furthermore, we applied a semi-structured interview (Vela, 2001) to a non-probabilistic sample of $58 \%$ of the community's 80 families. Men and women were selected for interviews based on availability and personal interest. Information obtained provided a community perspective on natural resources and their limits, the importance of institutions in internal management of projects, quality of services to which the community has access, the level of social tranquility within the community and cultural activities. This information was pondered using a scale of values ( 1 = very bad; $2=$ poor; $3=$ average; $4=$ good and 5 = very good) in order to graphically compare the perception of the producers and their wives regarding physical and social aspects of the community.

Vision of institutional representatives regarding cattle raising: In order to identify, the point of view of institutional actors regarding the most significant problems which affect cattle raising in the community, we applied a structural analysis (Mojica, 1991) which allows for determining the interdependence of problems mentioned by the actors and prioritizing them according to the capacity of a given problem to influence other problems. Representatives of the following institutions were interviewed in order to obtain the information used in the structural analysis: National Commission of Natural Protected Areas (CONANP), Autonomous University of Chiapas (UNACH), National Institute of Forestry and Agricultural Research (INIFAP), Mesoamerican Biological Corridor (CBM) and College of the Southern Frontier (ECOSUR).

We quantified interdependence among problems associated with cattle raising in the community by: identifying variables (problems associated with cattle raising in the community), determining the influence of each of these problems on the others and identifying the priority with which these problems should be attended to.

Indices of motricity (capacity of one problem to influence other problems) and dependence (to what extent one problem is a consequence of other problems) are expressed in percentages obtained through cross multiplication in which percentage is calculated for the value of motricity and dependence of each problem based on the value of the sum of rows and columns which should total $100 \%$ thus the total is divided by the percentage value of the problem in question and multiplied by 100 .

When one problem influences another, a motricity value of 1 is assigned and when there is no influence, a value of 0 is assigned. The sum of the data of the rows indicates the motricity value which indicates the number of problems influenced by the problem in question or the force which each problem has on the others.
In order to prioritize the problems, we graphed them according to their motricity and dependence indices. The graph was then divided into four quadrants defined as: zone of power, zone of conflict, zone of exit and zone of autonomous problems. In order to define the points of division for the quadrants, we applied the following equation (Mojica, 1991):

$$
\mathrm{m}=\frac{100}{\mathrm{n}}
$$

Where:

$\mathrm{m}=$ Point of division

$\mathrm{n}=$ Number of problems

\section{RESULTS AND DISCUSSION}

Analysis of community indicators: Based on the semistructured interview applied to husbands and wives of cattle raising families and some key informants, we obtained a scale of indicators related to different community aspects (Fig. 2). We observed that indicators related to natural resources obtained the highest values which reflects the importance producers assign to the community's natural resources. This coincides with that found by Guevara-Hernandez et al. (2008) in a community in the municipality of Villaflores, Chiapas where producers valorization of natural resources was also high. This coincidence may be due to the fact that members of both communities have been highly sensitized to natural resource issues as the members of each community live within the buffer areas of two different Biosphere Reserves: E1 Ocote and La Sepultura.

Figure 3 shows the results of the evaluation of indicators by the wives; these values are similar to those mentioned by the husbands with the exception of some indicators for example, tranquility in the community in which the wives perceive greater tranquility in the community than their husbands. This may be explained by the fact that the men are more involved with addressing community problems which coincides with that reported by Guevara (2007). The indicator importance

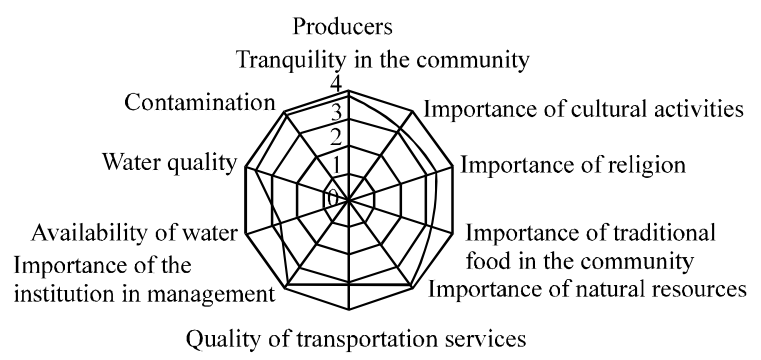

Fig. 2: Valorization of indicators by producers of the community Ach' lum, Ocozocoautla, Chiapas 


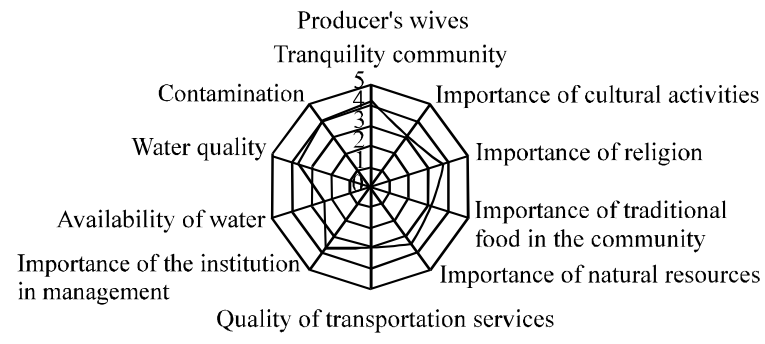

Fig. 3: Valorization of indicators by producers' wives in the community Ach' lum, Ocozocoautla, Chiapas

of institutions in management which was more highly valued by husbands than wives indicates that the husbands place greater importance on institutions which intervene in the community perhaps because they have more of a relationship to these institutions because they have more information regarding institutional projects or because they directly receive the benefits of these institutions, as pointed out by Nuijten (2003). Based on this finding, the husbands were asked to name those institutions which they considered to be of greatest importance in the community for inclusion in the structural analysis. Thus, five institutions were selected: CONANP, UNACH INIFAP, CBM and ECOSUR. Hernandez (2010) in a study on the same community reports the same institutions as those which have supported or directed some community project although, she reports that the producers perceive UNACH and CONANP as having the greatest presence in the community. In terms of local development processes, once local actors become involved in collective action, their identities are made visible. This represent the construction of external actors which work in a collective or individual manner according to Long (2001) and Guevara (2007). This idea is reinforced by the fact that producers mentioned that social strengthening has occurred as a result of these institutions' setting up field schools which stimulated creation of community actors in agricultural development (Guevara-Hernandez et al., 2011) including the organization of two groups of producers to obtain financing and implement cattle raising projects. Approximately, $52 \%$ of the community's cattle farmers have supported natural resource conservation by establishing protein banks with fodder trees including a plantation of $>60,000$ saplings of species found in the community (Leucaena leucocephala and Gliricidia sepium) which have a high fodder potential and by sensitizing other community members to value such forest resources (Gomez et al., 201 0; Nahed-Toral et al., 2010).

Adoption of the so called Cuban grasses CT-115 and OM-22 (Penisetum purpureum) over the past 3 years has generated a source of additional income for producers due to the fact that some members of the community sell grass stems for propagation to producers of neighboring communities. Additionally, the community benefited economically by acquiring a scale for weighing cattle for which financing was obtained by a group of community producers from CONANP. This scale allows the producers to obtain a better sale price for their animals due to the fact that the animals no longer lose weight due to long walks to take them elsewhere to be weighed and sold. Furthermore, there has been considerable growth in infrastructure and equipment given that projects financed by the institutions mentioned have allowed producers to construct corrals and fodder choppers. These projects have been successful in terms of financing, negotiation and collaboration among actors and should serve as a model for other communities. However, these projects have involved hours of travel and negotiations with decision makers of various political and administrative levels. For example initially CONANP had no interest in helping the community to acquire a scale. However, when a group of producers organized to express their interest in devoting an area to house the scale as well as materials and labor required to install necessary infrastructure, CONANP agreed to carry out the necessary paperwork. In this case, the success of this project resulted on the one hand from the community's insistence in improving the financial viability of the production system and on the other hand, from the institution's insistence on prioritizing conservation over production. During negotiations, the different points of view of external actors with respect to the process of development of local cattle raising and differing perceptions of the community and institutions led to obstacles in decision making which in turn led the parties to discuss possible solutions and come up with a joint scenario based on consensus to improve both the community's economic and environmental conditions.

This example demonstrates that since initially divergent visions or perceptions existed among community and institutional actors with respect to needs or problems regarding cattle raising, force fields were generated as described by Nuijten $(2004,2005)$ and Guevara (2007), since at some points during the process, certain tensions developed among external actors or between external and community actors. Such force fields were diffused once the opinions of producers and other local actors began to be understood and taken into account by one of the institutional actors who had a more systemic vision of the process and from that point, other external actors began to accept the producers' demands regarding technology development and implementation. Thus, the producers' needs were set as priorities in the institutions' agendas, benefitting all. 
Table 1: List of problems mentioned by institutions related to cattle raising in the community Ach' lum, Ocozocoautla, Chiapas

\begin{tabular}{llc}
\hline Problems & Institutions which mention the problem & No. of instiutions which mention the problem \\
\hline Inadequate cattle management & CONANP, INIFAP, CBMM and UNACH & 4 \\
Extensive cattle raising & CBMM, UNACH and CONANP & 3 \\
Lack of technical assistance & ECOSUR, CBMM and UNACH & 3 \\
Lack of marketing channels & CONANP, ECOSUR and UNACH & 3 \\
Growth of areas devoted to cattle raising & UNACH and ECOSUR & 2 \\
Cattle raising does not function as a viable economic system & INFAP andCONANP & 2 \\
Lack of organization among producers & CBMM and UNACH & 2 \\
Lack of agricultural diversification & ECOSUR and UNACH & 2 \\
Difficulty understanding advisory due to language & CONANP & 1 \\
Lack of homogeneity in cattle breed & CONANP & 1 \\
Plot dispersion & CONANP & 1 \\
Lack of inter-institutional coordination & CONANP & 1 \\
Lack of product quality & ECOSUR & 1 \\
Lack of public policies which promote & ECOSUR & 1 \\
environmentally friendly cattle raising & & 1 \\
Lack of economic reinvestment & ECOSUR & 1 \\
Lack of adoption of alternative technologies & CBMM & 1 \\
Lack of variety of cattle products & UNACH & 1 \\
Negative impacts on natural resources due & UNACH & 1 \\
to growth of cattle herd & & 1 \\
Lack of alternative livestock market & UNACH & \\
Degradation of grazing areas & UNACH & \\
\hline
\end{tabular}

This experience demonstrates that the dynamics of a process are based on permanent negotiations among actors in which force fields created play a neutralizing role which sets in motion subsequent steps of the local development process as suggested by Mattiace (2001) and Guevara-Hernandez et al. (2011).

Problems associated with cattle raising according to institutional representatives: Table 1 shows the 20 problems identified by the institutions. This table shows that the majority of the institutional representatives agree on some of the problems such as inadequate management of cattle, extensive cattle raising, lack of marketing channels and growth in areas devoted to cattle raising. Meanwhile, other problems were mentioned by only one institution such as lack of institutional coordination, lack of alternative livestock markets, degradation of grazing areas, lack of economic reinvestment, lack of agricultural diversification, lack of product quality and plot dispersion. Differing perceptions among institutional representatives with respect to these problems are due to lack of knowledge of problems which are unrelated to the work of a given institution or to lack of knowledge of community dynamics. These differences in institutional perspectives are translated into force fields which sooner or later result in conflicts as pointed out by Nuijten (2003, 2005).

Producer perceptions identified by Hernandez (2010) in the same community as to the most important problems in cattle raising are very different from the opinions we gathered from institutional representatives. In Hernandez' study, producers perceived animal health, lack of infrastructure and lack of resources to invest in cattle raising to be most important. Hernandez' results show that producers differentially prioritize problems which affect cattle raising in their community, highlighting those which are directly associated with their animals and pastures while the institutions highlight more general problems often related to their area of research or the political-administrative objectives of their institutions. This provides a ripe opportunity for creation of such force fields as previously mentioned but also may cause development of socio-environmental innovations for cattle raising to follow contrasting courses among institutions depending on the interests and policies of the actors promoting these innovations.

A similar case is reported by Aguilar (2007) who mentions that the most pressing problems related to cattle raising in the Sepultura Biosphere Reserve (REBISE) according to local experts are: low level of technological development, few sources of financing, inappropriate management of grasses and cattle, lack of training and technical assistance and environmental deterioration. This coincides with the present study in terms of lack of adoption of alternative technologies, inadequate management of cattle, lack of technical assistance and negative impacts on natural resources due to growth of cattle herds. Coincidentally, the same type of force fields are manifested in the study as those reported by Guevara (2007) who emphasizes the role of external and internal actors of a community advances in local development in the REBISE.

Structural analysis of problems associated with cattle raising: Upon comparing the results of Table 1 and 2, it may be noted that motricity of the problems is not 
Table 2: Values for motricity and dependence of problems associated with cattle raising in Ach' lum, Ocozocoautla, Chiapas

\begin{tabular}{|c|c|c|c|c|c|c|c|c|c|c|c|c|c|c|c|c|c|c|c|c|c|}
\hline Problems & 1 & 2 & 3 & 4 & 5 & 6 & 7 & 8 & 9 & 10 & 11 & 12 & 13 & 14 & 15 & 16 & 17 & 18 & 19 & 20 & MOT** \\
\hline Inadequate cattle management & - & 0 & 0 & 0 & 0 & 0 & 1 & 0 & 0 & 0 & 1 & 0 & 0 & 0 & 0 & 1 & 0 & 1 & 0 & 1 & 5 \\
\hline Lack of inter-institutional coordination & 1 & - & 1 & 1 & 1 & 1 & 1 & 1 & 0 & 1 & 0 & 0 & 0 & 0 & 0 & 1 & 1 & 1 & 1 & 1 & 13 \\
\hline Lack of marketing channels & 1 & 0 & - & 1 & 0 & 0 & 1 & 0 & 0 & 0 & 1 & 0 & 0 & 0 & 0 & 1 & 1 & 0 & 1 & 0 & 7 \\
\hline $\begin{array}{l}\text { Cattle raising does not function as } \\
\text { a viable economic system }\end{array}$ & 1 & 0 & 1 & - & 0 & 1 & 1 & 0 & 0 & 0 & 1 & 0 & 0 & 0 & 0 & 1 & 1 & 0 & 1 & 0 & 8 \\
\hline Lack of technical assistance & 1 & 1 & 1 & 1 & - & 1 & 1 & 1 & 1 & 0 & 1 & 0 & 1 & 0 & 0 & 1 & 1 & 1 & 1 & 1 & 15 \\
\hline Extensive cattle raising & 1 & 0 & 0 & 0 & 1 & - & 0 & 1 & 0 & 0 & 1 & 0 & 0 & 0 & 0 & 1 & 1 & 1 & 0 & 0 & 7 \\
\hline Lack of adoption of alternative technologies & 1 & 1 & 1 & 1 & 1 & 1 & - & 0 & 0 & 0 & 0 & 0 & 0 & 0 & 0 & 1 & 1 & 1 & 1 & 1 & 11 \\
\hline Lack of organization among producers & 1 & 1 & 0 & 1 & 1 & 1 & 1 & - & 1 & 0 & 0 & 0 & 0 & 0 & 0 & 0 & 1 & 1 & 1 & 0 & 10 \\
\hline Lack of product quality & 0 & 0 & 0 & 0 & 0 & 0 & 0 & 0 & - & 1 & 0 & 0 & 0 & 0 & 0 & 0 & 0 & 0 & 1 & 0 & 2 \\
\hline $\begin{array}{l}\text { Lack of public policies which promote } \\
\text { environmentally friendly cattle raising }\end{array}$ & 0 & 1 & 1 & 1 & 1 & 1 & 1 & 1 & 1 & - & 0 & 0 & 0 & 0 & 0 & 1 & 1 & 0 & 1 & 0 & 11 \\
\hline Lack of economic reinvestment & 0 & 0 & 0 & 1 & 1 & 0 & 1 & 0 & 0 & 0 & - & 0 & 0 & 0 & 0 & 1 & 1 & 1 & 0 & 0 & 6 \\
\hline Lack of agricultural diversification & 0 & 0 & 0 & 0 & 0 & 0 & 0 & 0 & 0 & 0 & 0 & - & 0 & 0 & 0 & 0 & 0 & 0 & 0 & 0 & 0 \\
\hline $\begin{array}{l}\text { Difficulty understanding advisory due } \\
\text { to language }\end{array}$ & 1 & 0 & 0 & 0 & 1 & 0 & 1 & 0 & 0 & 0 & 0 & 0 & - & 0 & 0 & 0 & 0 & 0 & 0 & 0 & 3 \\
\hline Lack of homogeneity in cattle breed & 0 & 0 & 0 & 0 & 0 & 0 & 0 & 0 & 0 & 0 & 0 & 0 & 0 & - & 0 & 0 & 0 & 0 & 0 & 0 & 0 \\
\hline Plot dispersion & 0 & 0 & 0 & 0 & 0 & 0 & 0 & 0 & 0 & 0 & 0 & 0 & 0 & 0 & - & 0 & 0 & 0 & 0 & 1 & 1 \\
\hline Growth of areas devoted to cattle raising & 1 & 0 & 1 & 0 & 0 & 0 & 0 & 0 & 0 & 0 & 0 & 0 & 0 & 0 & 1 & - & 0 & 1 & 0 & 0 & 4 \\
\hline Lack of variety of cattle products & 0 & 0 & 1 & 0 & 0 & 0 & 0 & 0 & 1 & 0 & 1 & 0 & 0 & 0 & 0 & 0 & - & 0 & 1 & 0 & 4 \\
\hline $\begin{array}{l}\text { Negative impacts on natural resources } \\
\text { due to growth of cattle herd }\end{array}$ & 1 & 0 & 0 & 0 & 0 & 0 & 0 & 1 & 0 & 1 & 1 & 0 & 0 & 0 & 0 & 1 & 0 & - & 1 & 0 & 6 \\
\hline Lack of alternative livestock market & 0 & 0 & 1 & 1 & 0 & 0 & 0 & 0 & 1 & 0 & 1 & 0 & 0 & 0 & 0 & 1 & 1 & 0 & - & 0 & 6 \\
\hline Degradation of grazing areas & 0 & 0 & 0 & 0 & 0 & 0 & 0 & 0 & 0 & 0 & 0 & 0 & 0 & 0 & 0 & 1 & 0 & 1 & 0 & - & 2 \\
\hline DEP*** & 10 & 4 & 8 & 8 & 7 & 6 & 9 & 5 & 5 & 3 & 8 & 0 & 1 & 0 & 1 & 12 & 10 & 9 & 10 & 5 & 121 \\
\hline
\end{tabular}

MOT*: Motricity; DEP**: Dependence

associated with the level of agreement among institutions as to which problems are of greater importance. For example, lack of institutional coordination although, only mentioned by one institution (Table 1) influences 13 of the other problems mentioned (Table 2). Lack of technical assistance was mentioned by three institutions and affects 15 of the other problems. This indicates that the problems of greater motricity and their capacity to affect other problems does not coincide with the number of times they were mentioned by the institutions but rather with the attributes of each of these problems.

In a similar manner, the sum of the data of the columns indicates the dependence value which represents the number of problems which may influence the problem of interest. Thus, lack of institutional coordination was found to be influenced by four other problems while lack of technical assistance was influenced by seven others which means that although, both problems have the capacity to influence others (high motricity), lack of technical assistance is more greatly influenced by other problems and therefore its solution more greatly depends on the solution of other problems. Therefore, these two problems will be differentially prioritized. In this case if the different actors reach agreement (institutional coordination) on technologies and methodologies for technical assistance as well as mechanisms for obtaining resources necessary for providing technical assistance. they will more easily be able to resolve lack of technical assistance because there will be institutional coordination regarding this matter.
This discrepancy regarding lack of institutional coordination, lack of technical assistance and lack of organization among producers as well as the different strategies which each actor seeks to implement in order to attend to these problems could be generating force fields among institutions which limit the local development process, especially with respect to cattle raising in the community, due to the fact that each actor is contemplating or using different strategies to achieve their objectives which may be contradictory when carried out within the same social groups and territorial spaces.

Table 3 shows the indices of motricty and dependence expressed in percentages. The problems with the highest indices of motricty were: lack of technical assistance with $12.4 \%$, lack of inter-institutional coordination with $10.7 \%$, lack of public policies which promote environmentally friendly cattle raising and lack of adoption of alternative technologies both with an index of $9.09 \%$ and lack of organization among producers with $8.26 \%$. The problems with lesser motricity indices were lack of homogeneity in the cattle breed and lack of agricultural diversification with indices of $0 \%$. This reinforces that common visions, strategies and methods will allow for advancing more efficiently in processes of socio-environmental innovation in cattle raising in the community.

Nevertheless, in order to identify those problems which require immediate attention, we graphed each one in a Cartesian plane whose $\mathrm{Y}$ axis is the motricity index 
Table 3: Values and indices for motricity and dependence for problems associated with cattle raising in Ach' lum, Ocozocoautla, Chiapas

\begin{tabular}{lrrrr} 
& \multicolumn{3}{c}{$\begin{array}{c}\text { Motricity } \\
\text { Problems }\end{array}$} & \multicolumn{3}{c}{ Index Dependence Index } \\
Lack of technical assistance & 15 & 12.40 & 7 & 5.79 \\
Lack of inter-institutional coordination & 13 & 10.70 & 4 & 3.31 \\
Lack of public policies which promote & 11 & 9.09 & 3 & 2.48 \\
environmentally friendly cattle raising & & & & \\
Lack of adoption of alternative & 11 & 9.09 & 9 & 7.44 \\
technologies & & & & \\
Lack of organization among producers & 10 & 8.26 & 5 & 4.13 \\
Cattle raising does not function as & 8 & 6.61 & 8 & 6.61 \\
a viable economic system & & & & \\
Extensive cattle raising & 7 & 5.79 & 6 & 4.96 \\
Lack of marketing channels & 7 & 5.79 & 8 & 6.61 \\
Lack of economic reinvestment & 6 & 4.96 & 8 & 6.61 \\
Negative impacts on natural resources & 6 & 4.96 & 9 & 7.44 \\
due to growth of cattle herd & & & & \\
Lack of alternative livestock market & 6 & 4.96 & 10 & 8.26 \\
Inadequate cattle management & 5 & 4.13 & 10 & 8.26 \\
Lack of variety of cattle products & 4 & 3.31 & 10 & 8.26 \\
Growth of areas devoted to cattle raising & 4 & 3.31 & 12 & 9.92 \\
Difficulty understanding advisory & 3 & 2.48 & 1 & 0.83 \\
due to language & & & & \\
Lack of product quality & 2 & 1.65 & 5 & 4.13 \\
Degradation of grazing areas & 2 & 1.65 & 5 & 4.13 \\
Plot dispersion & 1 & 0.83 & 1 & 0.83 \\
Lack of agricultural diversification & 0 & 0.00 & 0 & 0.00 \\
Lack of homogeneity in cattle breed & 0 & 0.00 & 0 & 0.00 \\
Totals & 121 & 100.00 & 121 & 100.00 \\
\hline
\end{tabular}

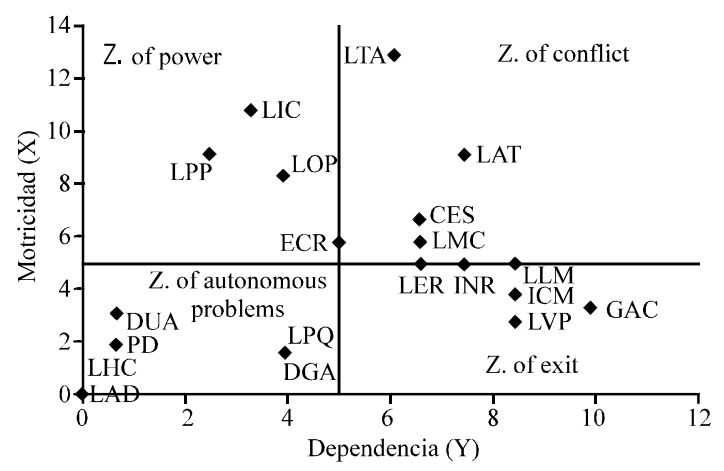

Fig. 4: Prioritorization of cattle raising problems in the community Ach'lum, Ocozocoautla, Chiapas

and $\mathrm{X}$ axis is dependence index. Figure 4 shows the four quadrants: zone of power, zone of conflict, zone of exit and zone of autonomous problems. The limits were defined as mentioned in the methodology with an indicative measure for separating the zones. The zone of power includes those problems which have the highest motricity $(>5 \%)$ and the lowest dependence $(<5 \%)$. These are the problems of greatest importance which require immediate attention because if resolved, the majority of the others will be indirectly resolved. Lack of interinstitutional coordination, lack of public policy which promotes environmental friendly cattle raising and lack of organization among producers are very significant problems which are not greatly affected by changes in other problems which means that solving these will indirectly contribute to solving other problems identified. This indicates that lack of institutional coordination, public policy and organization among producers are the most pressing areas for improving cattle production in the community. In this case, the institutions should organize in order to jointly carry out development strategies such as strengthening local organization so that in the long run producers themselves propose solutions to any given problem and institutions support those problem solving processes which the producers have mutually agreed upon.

The zone of conflict includes problems of high motricity $(>5 \%)$ and high dependence $(>5 \%)$. These are strong but also greatly affected by other problems. They also have an effect on other problems including those in the same zone. Their importance lies in the fact that any variation in these problems will influence the other problems in this zone as well as those in the zone of exit due to the fact that those problems in the zone of exit are low in motricity and high in dependence. This implies that the problems in this zone may be solved indirectly by resolving those problems of high motricity. This aspect is very important from the perspective of force fields because if different institutions address these problems from divergent perspectives, conflicts may be generated among institutions or between institutions and the community due to different strategies of action. This coincides with that reported by Guevara-Hernandez et al. (2010) in a cattle raising community in the Sepultura Reserve.

The zone of exit includes all those problems which are a product of the former problems. This zone is characterized by low motricity $(<5 \%)$ but high dependence $(>5 \%)$ and includes problems such as growth of areas dedicated to cattle raising which is very important at a community and reserve level given that according to CONANP-SEMARNAT (2001), cattle raising is one of the greatest threats to nature reserves. Nevertheless, the magnitude of this growth is directly related to other problems such as lack of agricultural diversification and predominance of extensive cattle raising in the community. There is a greater risk of accelerated growth of the cattle raising frontier in reserves if extensive cattle raising prevails and if no alternative markets exist to motivate development of other types of economic activities.

The zone of autonomous problems is thus referred to because the problems of this zone do not significantly influence others nor are they influenced by others. For this reason, they have a low motricity $(<5 \%)$ and low dependence $(<5 \%)$ that is they are fairly independent 
problems. This zone includes for example, lack of agricultural diversification which institutions have tended to address independently of other problems which they mentioned. Although, the fact that the producers are not familiar with other economic alternatives which could improve their incomes, lack of diversification could favor as previously mentioned, growth of the cattle raising frontier and resulting consequences.

As a whole, the cattle raising situation for indigenous communities of this area of the state of Chiapas is very similar to that described by Lopez et al. (2000) in the Northern region of the state. Overgrazing of pastures, deficient cattle management, lack of cattle raising knowledge and deforestation in this region resemble problems found in this study such as degradation of grazing areas inadequate cattle management, lack of technical assistance and negative impacts on natural resources due to growth of cattle herds. This is the result of force fields created by the actors working in the zone who have not found a way of joining forces to work in a collective manner with a common vision in a geographic area which transcends a single community.

The research of Aguilar (2007) mentions a series of cattle raising problems in La Sepultura Biosphere Reserve. These problems are very similar to those found in the study, particularly negative impacts on natural resources due to growth of cattle herds inadequate cattle management and lack of technical assistance. Also Alvarez (1991) in Bochil and Chiapas and Figueroa (1997) in Mapastepec, Chiapas report lack of technical assistance as a pressing problem.

Therefore, besides providing a space for learning in action, the creation of spaces for collective action through platforms of permanent dialogue among actors internal or external to the community represents an effective way of attending to pressing problems of natural protected areas under consensual multi-institutional schemes where dialogue and respect for the efforts of all actors predominate.

\section{CONCLUSION}

The principal problems regarding cattle raising in this community in the zone of power were lack of interinstitutional coordination, lack of public policy which promotes environmental cattle raising and lack of organization among producers. The prioritization of problems identified in this study demonstrates, on the one hand, the importance of institutions working together to solve problems of high motricity. Thus, through collective action, producers and institutions may define actions or strategies which could influence decision makers, legislators and other political actors in favor of sustainable cattle raising. On the other hand, it is necessary to foment mechanisms for training and organization of producers which favor inter-institutional coordination and synergy which could magnify the impact of projects. These actions could lead to transition from extensive management of cattle raising toward more intensified and sustainable management. Internal organization of groups of producers and complementarity of institutional actions would magnify the efficiency of the results of projects and economic resources oriented toward this project. Internal organization of groups of producers and complementarity of institutional actions would magnify the efficiency of the results of projects and economic resources oriented toward this project.

In order to achieve this, researchers must maintain a close alliance through networks of scientific and technological cooperation for technological innovation in the search and implementation of strategies and platforms for research and diffusion of knowledge of environmental friendly cattle raising and mitigation of climate change.

\section{NOMENCLATURE}

LTA = Lack of technical assistance

LIC = Lack of inter-institutional coordination

$\mathrm{LPP}=$ Lack of public policies which promote environmentally friendly cattle raising

LOP = Lack of organization among producers

LAT = Lack of adoption of alternative technologies

LLM = Lack of alternative livestock market

ICM = Inadequate cattle management

$\mathrm{GAC}=$ Growth of areas devoted to cattle raising

LVP = Lack of variety of cattle products

CES = Cattle raising does not function as a viable economic system

$\mathrm{LMC}=$ Lack of marketing channels

INR = Negative impacts on natural resources due to growth of cattle herd

$\mathrm{LER}=$ Lack of economic reinvestment

$\mathrm{ECR}=$ Etensive cattle raising

$\mathrm{LPQ}=$ Lack of product quality

DGA $=$ Degradation of grazing areas

DUA $=$ Difficulty understanding advisory due to language

$\mathrm{PD}=$ Plot dispersion

LHC = Lack of homogeneity in cattle breed

$\mathrm{LAD}=$ Lack of agricultural diversification 


\section{REFERENCES}

Aguilar, M.S., 2007. Effect of programs promoting cattle raising in the Sepultura Biosphere Reserve, Villaflores, Chiapas. Undergraduate Thesis, University of Sciences and Arts Chiapas, Tuxtla Gutierrez, Chiapas, Mexico.

Alvarez, D.A.E., 1991. Diagnostic study of cattle raising in the municipality of Bochil, Chiapas. Undergraduate Thesis, Autonomous University of Chiapas, Tuxtla Gutierrez, Chiapas, Mexico.

Bourdieu, P., 1985. The social space and the genesis of groups. Theory Soc., 14: 723-744.

Braun, A.R., G. Thiele and M. Fernandez, 2000. Farmer field schools and local agricultural research committees: Complementary platforms for integrated decision-making in sustainable agriculture. Agricultural Research and Extension Network (AgREN-ODI), Network Paper No. 105, pp: 1-20.

CONANP-SEMARNAT, 2001. Management program for the Selva El Ocote biosphere reserve. CONANPSEMARNAT, Mexico, pp: 21.

Figueroa, N.J., 1997. Cattle raising in the municipality of Mapastepec, Chiapas. Diagnostic study. Undergraduate Thesis, Autonomous University of Chiapas, Villaflores, Chiapas, Mexico.

Gaventa, J., 2004. Towards Participatory Local Governance: Assessing the Transformative Possibilities. In: Participation: from Tyranny to Transformation, Exploring New Approaches to Participation in Development, Hickey, S. and G. Mohan (Eds.). ZED Books, London, UK., pp: 25-41.

Gerritsen, P.R.W., 2002. Diversity at stake: A farmers perspective on biodiversity and conservation in Western Mexico. Ph.D. Thesis, Department of Social Sciences, Wageningen University, Wageningen, The Netherlands.

Gomez, C.H., 1996. Analysis of the agricultural situation: Sheep raising in the Chiapas highlands. Internal Report of ECOSUR, San Cristobal de las Casas, Chiapas, Mexico.

Gomez, C.H., R.R. Pinto, H.F. Guevara, J.F.J. Medina, T.J. Nahed, S.B. Ruiz and N.P. Mendoza, 2010. Local innovation of silvopastoral systems: Contribution to productive reconversion of cattle raising areas. Autonomous University of Chiapas, Tuxtla Gutierrez, Mexico, pp: 81.

Gomez, C.H., T.J. Nahed, R.R. Pinto, H.F. Guevara and J.F.J. Medina, 2011. Agroforestry in a Community in the Buffer Zone of the El Ocote Biosphere Reserve. In: Alternatives for Sustainable Cattle Raising Reconversion, Palma, G., T. Nahed and G. Sanginez (Eds.). University of Colima, Colima, Mexico, pp: 187.
Guevara, H.F., 2007. Action-research and ethnography on governance, actors and development in Southern Mexico. Ph.D. Thesis, Wageningen University, The Netherlands.

Guevara-Hernandez, F., J. Ovando-Cruz, N.M. McCune, R. Pinto-Ruiz, J.F. Medina-Jonapa and H. GomezCastro, 2010. Participatory power mapping: A collective identification of development actors in a small cattle village of Chiapas, Mexico. Int. J. Technol. Dev. Stud., 1: 5-28.

Guevara-Hernandez, F., N.M. McCune, C.H. Gomez, R.R. Pinto, J.F.J. Medina, L.A. Hernandez and C.C. Tejeda, 2011. Conflicting regulatory systems for natural resources management in Southern Mexico: An ethnographic case study. Int. J. Technol. Dev. Stud., 2: 30-62.

Guevara-Hernandez, F., R. Pinto-Ruiz, H. Gomez-Castro and F.J. Medina-Jonapa, 2008. Local perceptions on empowerment and development in a remote village of Chiapas, Mexico. Tailoring Biotechnol. J., 4: $71-94$.

Hernandez, G.J.A., 2010. Dotation of capitals of the community and its relationship to intervention by institutions in agro-ecosystems of Tierra Nueva, Ocozocoautla, Chiapas. Masters Thesis, Tropical Agronomic Center of Research and Teaching (CATIE).

Hernandez, L.M.H., 2009. Evaluation and persepctives on silvopastoral projects in the community Tierra Nueva, Ocozocoautla Chiapas. Undergraduate Thesis, Faculty of Agronomic Sciences, Autonomous University of Chiapas, Mexico.

Long, N. and A. Long, 1992. Battlefields of Knowledge: The Interlocking of Theory and Practice in Social Research and Development. Routledge, London, UK., ISBN-13: 9780415072069, Pages: 306.

Long, N. and M. Villareal, 1994. The Interweaving of Knowledge and Power in Development Interfaces. In: Beyond Farmers First: Rural People's Knowledge, Agricultural Research and Extension Practice, Scoones, I. and J. Thompson (Eds.). Intermediate Technology Publications, London, UK., pp: $41-52$.

Long, N., 2001. Development Sociology: Actor Perspectives. 1st Edn., Routledge, London, ISBN-13: 978-0415235365, pp: 232.

Lopez, C.M., F.G. Jimenez, B. de Jong, G.S. Ochoa and J.N. Toral, 2000. The mountain cattle raising system in the North-Tzotzil region of Chiapas, Mexico. College of the Southern Frontier, San Cristobal de Las Casas, Chiapas, Mexico. 
Mattiace, S.L., 2001. Regional renegotiations of space Tojolabal ethnic identity in Las Margaritas, Chiapas. Lat. Am. Perspect., 28: 73-97.

Mojica, S.F., 1991. Perspectives; Techniques for Visualizing the Future. LEGIS, Bogota, Colombia, pp: 35-68.

Mosse, D., 1999. Colonial and contemporary ideologies of community management: The case of tank irrigation development in South India. Mod. Asian Stud., 33: $303-338$.

Mosse, D., 2004. Is good policy unimplementable? Reflections on the Ethnography of aid policy and practice. Dev. Change, 35: 639-671.

Murphy, W.P., 1990. Creating the appearance of consensus in Mende political discourse. Am. Anthropol., 92: 24-41.

Nahed, T.J., 1999. Alternatives for development of sustainable sheep production systems in the Chiapas highlands. Ph.D. Thesis, National Autonomous University of Mexico, Mexico.

Nahed-Toral, J., H. Gomez-Castro, R. Pinto-Ruiz, F. Guevara-Hernandez, F. Medina-Jonapa, M. Ibrahim and D. Grande-Cano, 2010. Research and development of silvopastoral systems in a village in the buffer zone of the El Ocote Biosphere Reserve, Chiapas, Mexico. Res. J. Biol. Sci., 5: 499-507.
Nuijten, M., 2003. Power, Community and the State: The Political Anthropology of Organization in Mexico. Pluto Press, London, UK., ISBN-13: 9780745319476 , Pages: 227.

Nuijten, M., 2004. Between fear and the fantasy: Governmentality and the working of power in Mexico. Critique Anthropol., 24: 209-230.

Nuijten, M., 2005. Power in practice: A force field approach to natural resource management. $\mathrm{J}$. Transdiscipinary Environ. Stud., 4: 1-14.

Pijnenburg, B., 2004. Keeping it vague: Discourses and practices of participation in rural Mozambique. Ph.D. Thesis, Department of Social Sciences, Wageningen University. Wageningen, The Netherlands.

Vela, F., 2001. A Basic Methodological Action of Social Research: The Qualitative Interview. In: Observe, Learn and Comprehend: Regarding the Qualitative Tradition in Social Research, Tarres, M.L. (Ed.). Porrua y FLACSO, Mexico, pp: 63-95.

Wells, M.J., 1983. Meditation, dependency and the goals of development. Am. Ethnol., 10: 770-788. 